\title{
OLHANDO UM PASSO ADIANTE: O EFEITO DA INFORMAÇÃO CONTÁBIL EM VARIÁVEIS MACROECONÔMICAS NO BRASSIL
}

\author{
LOOKING A STEP AHEAD: THE EFFECT OF ACCOUNTING INFORMATION \\ ON MACROECONOMIC VARIABLES IN BRAZIL
}

\author{
ANDRÉ SEKUNDA \\ Universidade Federal da Paraíba. Endereço: Cidade Universitária, S/N | \\ 58051-900| João Pessoa/PB | Brasil. \\ (1) http://orcid.org/0000-0001-9684-8353 \\ andresekunda@gmail.com
}

\author{
JOSÉ RICARDO REVOREDO DA SILVA \\ Universidade Federal da Paraíba. Endereço: Cidade Universitária, S/N | \\ 58051-900| João Pessoa/PB | Brasil. \\ (D)http://orcid.org/0000-0002-3492-1161 \\ rich.revoredoo@gmail.com
}

\section{EDILSON PAULO}

Universidade Federal do Rio Grande do Sul. Endereço: Avenida João Pessoa, 52 - sala 44 | Centro Histórico | 90040-000 | Porto Alegre/RS | Brasil. (1) http://orcid.org/0000-0003-4856-9039

e.paulo@uol.com.br

\section{RESUMO}

Este trabalho analisa o efeito de choques em variáveis contábeis em um conjunto de variáveis macroeconômicas no cenário brasileiro, partindo do pressuposto da utilidade da informação contábil e do seu potencial efeito sobre a economia. Na pesquisa, são analisadas as seguintes variáveis macroeconômicas: produto interno bruto (PIB), desemprego e taxa básica de juros (Selic). A pesquisa, de natureza quantitativa, emprega modelos de vetores autorregressivos (VAR) para verificar o efeito de choques de variáveis contábeis (fluxo de caixa operacional; lucro antes de juros e impostos - Ebit; lucro líquido; e patrimônio líquido) sobre as variáveis macroeconômicas brasileiras no período de 2000 a 2019, analisando ao todo 79 trimestres. O pressuposto da pesquisa, com base na literatura prévia, é que a informação contábil carrega em si elementos informativos da economia real, sendo capaz, portanto, de predizer movimentos das variáveis macroeconômicas, tais como o PIB (Konchitchki \& Patatoukas, 2014a; Brito, 2017; Silva, 2019); inflação (Shivakumar \& Urcan, 2017) e emprego (Hann, Li \& Ogneva, 2017; Nallareddy \& Ogneva, 2017), dentre outras. Como principais resultados, choques nas variáveis contábeis produzem efeitos até cinco trimestres depois e logo se dissipam. Choques no lucro líquido e Ebit produzem efeitos positivos no PIB e choques no caixa operacional reduzem o desemprego na maior parte do tempo, enquanto que choques no Ebit produzem pouco efeito sobre a Selic. Os achados evidenciam, em especial, a capacidade da informação contábil de antecipar movimentos nas variáveis macroeconômicas, constituindo uma alternativa viável para análise 
dessas macrovariáveis, servindo como ferramenta adicional no processo de tomada de decisão, em especial para decisões ligadas a investimento, bastante sensíveis às instabilidades econômicas.

Palavras-chave: Macroaccounting. Séries temporais. Informação contábil.

\begin{abstract}
This work analyzes the effect of shocks on accounting variables on a set of macroeconomic variables in the Brazilian scenario, based on the assumption of the usefulness of accounting information and its potential effect on the economy. In the survey, the following macroeconomic variables are analyzed: gross domestic product (GDP), unemployment and basic interest rate (Selic). The research, of a quantitative nature, uses vector autoregression (VAR) models to verify the effect of shocks of accounting variables (operating cash flow; earnings before interest and taxes - Ebit; net income; and shareholders' equity) on Brazilian macroeconomic variables from 2000 to 2019, analyzing 79 quarters in all. The research assumption, based on the previous literature, is that the accounting information carries informational elements of the real economy, being able, therefore, to predict movements of macroeconomic variables, such as GDP (Konchitchki \& Patatoukas, 2014a; Brito, 2017; Silva, 2019); inflation (Shivakumar \& Urcan, 2017) and employment (Hann, Li \& Ogneva, 2017; Nallareddy \& Ogneva, 2017), among others. As main results, shocks in the accounting variables take effect up to five quarters later and soon dissipate. Shocks in net income and Ebit have positive effects on GDP and shocks in operating cash reduce unemployment most of the time, while shocks in Ebit have little effect on the Selic. The findings show, in particular, the ability of accounting information to anticipate movements in macroeconomic variables, constituting a viable alternative for the analysis of these macrovariables, serving as an additional tool in the decision-making process, especially for investment-related decisions, which are very sensitive to economic instabilities.
\end{abstract}

Keywords: Macroaccounting. Time Series. Accounting information.

\title{
1 INTRODUÇÃO
}

Este trabalho possui raízes na pesquisa de Ball e Brown (1968), que discutiram, em síntese, as propriedades e a utilidade da informação contábil. Embora eles não tenham realizado diretamente a análise pretendida nesta pesquisa, ela é possível, em grande medida, graças à sua influência. Os números contábeis são úteis para uma série de decisões. Desde a alocação eficiente de recursos em ações, até a tomada de decisões relativas à estrutura de capital de empresas, muitas decisões passam pela análise da informação contábil. Ou seja, esta possui uma gama de utilidades com potencial para explicar o comportamento de muitas situações usuais no quotidiano das corporações.

Nesse sentido, conforme relatam Kothari e Wasley (2019), uma nova vertente de pesquisas contábeis associa a informação contábil à previsão de variáveis macroeconômicas, como o PIB, por exemplo. Isto é, passou-se a investigar o potencial da informação contábil para explicar e até mesmo melhorar a previsão de informações macroeconômicas. Essa linha de investigação vem sendo denominada de macroaccounting.

Pesquisas recentes fornecem evidências de que a informação contábil no nível da firma pode antecipar movimentos futuros de indicadores macroeconômicos, como crescimento do PIB (Konchitchki \& Patatoukas, 2014a; Brito, 2017; Silva, 2019); inflação (Shivakumar \& Urcan, 2017) e no emprego (Hann, Li \& Ogneva, 2017; Nallareddy \& Ogneva, 2017).

Com isso, a pesquisa investiga o efeito no PIB, desemprego e taxa básica de juros da economia (Selic) quando da ocorrência de choques em informações contábeis no nível da firma. 
As variáveis contábeis testadas são o fluxo de caixa operacional, o lucro líquido (LL), o lucro antes de juros e impostos (earnings before interest and taxes - Ebit) e o patrimônio líquido (PL).

O fluxo de caixa operacional foi selecionado por evidenciar a capacidade de a empresa gerar recursos para financiar seus principais gastos operacionais. Supõe-se que empresas com maiores folgas de caixa terão recursos à disposição para expansões de suas operações. Com isso, havendo um choque nesse caixa no nível da firma, espera-se que haja resposta no nível agregado (variáveis macroeconômicas).

Ebit e LL constituem duas métricas importantes sobre o desempenho das firmas. O primeiro muito associado ao resultado operacional, e o segundo associado ao desempenho da firma após deduzidos todos os custos e despesas (inclusive as financeiras e tributárias) de suas operações. Presume-se que os resultados operacional e líquido afetem o nível agregado (Konchitchki \& Patatoukas, 2014a; Brito, 2017; Silva, 2019). Por essa razão, investiga-se o efeito que choques nessas variáveis geram na informação macroeconômica.

Por fim, o PL também foi incluído na análise por representar o patrimônio residual da firma, após deduzidas todas as dívidas, refletindo toda a riqueza líquida da empresa, o que inclui seu capital e os lucros acumulados ao longo dos anos. Além disso, é uma proxy para o tamanho da firma. Quanto maior o PL, maior a companhia. Dessa maneira, supõe-se que quanto maior o tamanho da firma (mensurado pelo PL), maiores tendem a ser as reações sobre as variáveis macroeconômicas quando da ocorrência de choques nessa variável. Ainda segundo Brito (2017), no nível agregado, o PL é uma medida de desempenho econômico-financeiro significativa para a análise macroeconômica.

Com isso, justifica-se o emprego das variáveis contábeis modeladas na pesquisa. Quanto à escolha das variáveis macroeconômicas, analisa-se o efeito de choques nas variáveis contábeis sobre o PIB, desemprego e Selic, variáveis que possuem reflexo direto sobre o dia a dia das empresas e de diversos players do mercado. Por isso, compreender movimentos ligados a elas pode contribuir para reduzir incertezas, que são, segundo a teoria econômica, algumas das principais fontes de efeitos contracionistas sobre a economia, prejudicando em especial decisões de investimento, necessárias para o crescimento econômico (Barboza \& Zilberman, 2018).

Antecipar movimentos dessas variáveis macroeconômicas, ainda que pequenos, pode contribuir para redução dessa incerteza e melhoria da alocação de recursos pelos players do mercado. Como estimar o PIB, desemprego e Selic não é um processo fácil, tampouco barato e acessível, a pesquisa parte de uma alternativa mais simples: verificar o efeito, nessas variáveis, de choques em números contábeis, o que constitui uma alternativa para entender o comportamento das variáveis macroeconômicas a partir da análise da informação contábil.

Para tanto, a pesquisa emprega modelos de vetores autorregressivos (VAR) para condução das análises, realizando toda a série de procedimentos econométricos a eles atrelados, como testes de estacionariedade, análise de defasagens, testes de especificação dos modelos e demais procedimentos relacionados.

Realiza-se a análise por meio da função impulso-resposta (IRF), visando atender ao objetivo principal da pesquisa: analisar o efeito, nas variáveis macroeconômicas, de choques na informação contábil para o cenário brasileiro. Além disso, realiza-se a decomposição da variância desses indicadores, visando verificar a contribuição de cada variável contábil para explicação da variação nos indicadores macroeconômicos. Por fim, realiza-se um teste de causalidade de Granger, a fim de verificar se as informações contábeis causam (ou não), no sentido de Granger, as variáveis macroeconômicas.

Como contribuição, a pesquisa auxilia no processo de tomada de decisão, em especial de investimento, buscando compreender movimentos das variáveis macroeconômicas por meio de choques nas variáveis contábeis.

O melhor entendimento das condições macroeconômicas da economia melhora o processo de alocação de recursos na economia. A literatura sugere que problemas no ambiente econômico, como níveis de incerteza altos, deixam investidores e empresas mais resistentes à realização de 
novos investimentos, levando a um adiamento desse processo de alocação de recursos, que pode levar a diminuições na contratação de pessoal, bem como no volume de produção, afetando o crescimento econômico (Bloom, Floetotto, Jaimovich, Saporta-Eksten \& Terry, 2012; Kalay, Nallareddy \& Sadka, 2016).

Portanto, com o emprego da informação contábil, busca-se ver, alguns passos adiante, como poderá ser o comportamento da economia, o que pode contribuir para uma melhor tomada de decisão. No caso específico desta pesquisa, emprega-se a informação contábil para analisar PIB, desemprego e Selic, importantes variáveis macroeconômicas capazes de influenciar decisões de investimento de diversos players do mercado.

Além disso, este trabalho amplia a pouco explorada literatura sobre macroaccounting, em especial trazendo à discussão a análise da causalidade de Granger, até então inexplorada em pesquisas nacionais sobre o tema.

O artigo possui a seguinte estrutura: esta introdução, uma revisão da literatura, uma seção metodológica, a discussão dos resultados e as considerações finais.

\section{REVISÃO DA LITERATURA}

Desde a pesquisa de Ball e Brown (1968), diversos outros estudos se concentraram na relevância das informações contábeis nas mais distintas áreas da literatura contábil. No entanto, os trabalhos pouco analisam a relação entre as informações contábeis e macroeconômicas, principalmente sob a ótica "micro-macro", que aponta uma influência do nível empresa (micro) nos resultados macroeconômicos. Isto posto, Ball e Sadka (2015) afirmam que existe uma convergência entre a macroeconomia e a pesquisa contábil. Corroborando essa afirmação, Kothari e Wasley (2019) apontaram o surgimento de uma nova corrente de pesquisas em Contabilidade que examinam a magnitude dos dados contábeis e sua influência nas medidas macroeconômicas.

Nesse sentido, surge a corrente keynesiana, baseada no aspecto da demanda. Para Keynes (1936), as expectativas dos agentes envolvidos determinam as decisões acerca da atividade econômica de um país (investimento, produção e emprego). Isto é, os resultados macroeconômicos decorrem dos movimentos em conjunto, de modo agregado, das decisões tomadas em nível microeconômico. Assim, torna-se crível inferir que as informações contábeis são úteis nas análises de indicadores macroeconômicos (Silva, 2019).

Apoiadas nos aspectos teóricos defendidos por Keynes (1936), algumas pesquisas visaram verificar a importância das informações contábeis no cenário macroeconômico: no PIB (Konchitchki \& Patatoukas, 2014a; Konchitchki \& Patatoukas, 2014b; Brito, 2017; Silva, Paulo, Bianchi \& Queiroz, 2018; Silva, 2019); na inflação (Shivakumar, 2007; Cready \& Gurun, 2010; Kothari, Shivakumar \& Urcan, 2013; Shivakumar \& Urcan, 2017); e no emprego (Hann, Li \& Ogneva, 2017; Nallareddy \& Ogneva, 2017).

O estudo de Konchitchki e Patatoukas (2014a) analisou o relacionamento entre as informações contábeis, isto é, os lucros contábeis agregados, e o cenário macroeconômico, representado pelo PIB dos Estados Unidos. Eles concluíram que o crescimento agregado dos lucros contábeis é um importante indicador de crescimento do PIB nominal. Além disso, os autores examinaram se as informações contábeis, por meio dos indicadores de rentabilidade agregada, são oportunas na previsão do PIB real (Konchitchki \& Patatoukas, 2014b). Novamente, os resultados demonstraram que a análise das informações contábeis aplicadas no nível agregado é útil para avaliar as perspectivas macroeconômicas.

Brito (2017) analisou a relação entre as informações contábeis, por meio de indicadores de desempenho e algumas variáveis contábeis (ativo total, lucro líquido, patrimônio líquido e receita líquida), e o crescimento econômico, representado pelo PIB. A autora verificou que as variáveis contábeis foram preditivas em explicar o PIB real, sendo o ROE (return on equity), patrimônio e lucro líquido as de maior significância. 
Ainda pela ótica do PIB, Silva et al. (2018), empregando o método DuPont, analisaram a relação entre a rentabilidade agregada (RNOA) das firmas brasileiras e a atividade econômica, investigando como esse relacionamento se comporta nos períodos de expansão e recessão. Observou-se, inicialmente, que existe influência dos indicadores do RNOA no crescimento econômico real e que esse impacto é mais consistente nas fases de crise econômica. Tais achados refletem a prerrogativa defendida por Keynes (1936), apontando a relevância das informações contábeis em nível agregado para predições macroeconômicas.

$\mathrm{Na}$ pesquisa de 2019, Silva buscou investigar pelo método DuPont não somente a influência da RNOA e seus direcionadores, como também outros indicadores de performance das empresas brasileiras e o PIB real, além de verificar esse comportamento das diferentes fases dos ciclos econômicos: expansão, recessão, contração e recuperação. Seguindo os achados dos demais estudos, verificou-se a influência das informações contábeis na dinâmica macroeconômica. No que se refere aos ciclos econômicos, os resultados apontaram para uma movimentação crescente da explicação do PIB real pelas variáveis contábeis nas fases de crescimento econômico (expansão e recuperação), diferentemente das fases de queda (recessão e contração), que apresentou uma relação decrescente.

Pela perspectiva da inflação, Shivakumar (2007) apresentou evidências preliminares de que os lucros agregados estão associados positivamente à inflação futura. Da mesma forma, Cready e Gurun (2010) encontraram que os lucros de empresas norte-americanas transmitem informações sobre inflação, pois os retornos dos títulos tendem a responder diretamente às expectativas futuras de inflação. Por sua vez, Kothari et al. (2013) investigaram, dentre alguns pontos, se os lucros contábeis são úteis na previsão da inflação. Mostrou-se que as surpresas nos lucros agregados possuem informações oportunas e relevantes sobre inflação futura, isto é, os lucros reportados além do que foi previsto pelos analistas em um determinado mês preveem erros futuros de previsão de inflação.

O trabalho de Shivakumar e Urcan (2017) propõe examinar empiricamente quais prováveis explicações e caminhos levam o crescimento agregado dos lucros a estar causalmente relacionado à inflação futura. Os autores chegaram a duas motivações, uma baseada na mudança de investimentos pelas empresas em resposta ao crescimento de suas lucratividades e a outra conforme o consumismo, uma vez que o crescimento agregado dos lucros pode alterar a riqueza das pessoas no curto prazo, mudando, assim, a curva de demanda por bens de consumo no nível agregado.

Por fim, quanto à taxa de emprego, Hann et al. (2017) examinaram a associação entre os lucros contábeis agregados e o mercado de trabalho, sendo a criação ou destruição do emprego uma das medidas verificadas. Os resultados sugerem que os lucros agregados contêm informações oportunas sobre a dinâmica do mercado de trabalho. As notícias sobre os lucros podem sinalizar mudanças persistentes na lucratividade das empresas, o que permite observar a criação e destruição total de empregos com até quatro trimestres à frente. Esses resultados indicam que as informações contábeis a um nível agregado possuem uma informatividade relevante sobre condições futuras do mercado de trabalho. A pesquisa de Nallareddy e Ogneva (2017) corrobora tal afirmação, ao documentar uma relação positiva entre notícias de lucros e mudanças futuras no emprego em nível de empresa.

\section{METODOLOGIA}

\subsection{Composição e tratamento dos dados}

O objetivo do estudo é analisar o efeito, nas variáveis macroeconômicas, de choques na informação contábil para o cenário brasileiro. Como vetor de variáveis contábeis, empregaram-se LL, Ebit, PL e caixa operacional das empresas brasileiras de capital aberto. Já quanto às variáveis macroeconômicas, tem-se o PIB, desemprego e Selic. Os dados empregados na pesquisa são 
trimestrais e o período analisado vai do primeiro trimestre de 2000 até o terceiro trimestre de 2019. Os dados contábeis das empresas foram coletados na Economatica. Já os dados relacionados às variáveis macroeconômicas foram coletados no portal Sidra-IBGE e no Ipea-Data, ambos portais públicos com informação disponível a qualquer pessoa.

Uma vez coletados os dados das empresas (variáveis contábeis), tratou-se dos outliers com winsorização a 5\%. Após esse tratamento, e seguindo o procedimento adotado por Konchitchki e Patatoukas (2014b), foi calculada a média de cada variável contábil por trimestre, trabalhando com o LL médio de todas as empresas por trimestre, o Ebit médio de todas as empresas por trimestre, e assim por diante. Após isso, as médias trimestrais foram logaritmizadas. Em seguida, testou-se a estacionariedade de cada uma das variáveis. Para tanto, foi empregado o teste de Dickey-Fuller, que tem por hipótese nula que a série temporal possui raiz unitária. Ao rodar o teste, nenhuma das variáveis mostrou-se estacionária em nível, sendo necessário diferenciá-las. Todas elas mostraramse estacionária em primeira diferença.

\subsection{Modelo de vetores autorregressivos (VAR)}

Como o trabalho envolve o manejo de séries temporais, adotou-se para este estudo as equações de um VAR. Inicialmente, buscou-se saber qual a ordem da defasagem do modelo VAR a ser estimado, analisando através dos critérios (AIC, HQIC e SBIC). No caso dos modelos discutidos neste trabalho, os testes indicaram uma defasagem de 4 lags segundo todos os critérios de análise e para todos os modelos.

Conhecida a ordem dos lags do modelo e uma vez que as variáveis são estacionárias, estimou-se o modelo de VAR, que permite analisar interrelações entre múltiplas variáveis, identificando o componente exógeno de cada variável e possibilitando a estimação do efeito de um choque nessa variável sobre as demais (Cavalcanti, 2010). O VAR pode ser expresso conforme Equação (1) (Giordano, Momigliano, Neri \& Perotti, 2007):

$$
X_{t}=B(L) X_{t-1}+U_{t}
$$

Em que $X_{t}$ é o vetor de variáveis, B(L) é um polinômio autoregressivo de lags e $U_{t}$ é o vetor de inovações. Salientando que o modelo VAR é rodado com o número de lags identificado nos testes previamente realizados, seguindo os critérios decisoriais já mencionados (AIC, HQIC, SBIC e outros). Para cada variável macroeconômica analisada (PIB, Selic e desemprego), rodouse um VAR com um vetor de variáveis contábeis (LL, Ebit, PL e caixa operacional).

A modelagem VAR é dada por meio de repetições até que se encontre o modelo mais adequado. Para o modelo ser considerado adequado é preciso realizar os testes de diagnóstico dos resíduos: a normalidade (teste de Jarque-Bera), heterocedasticidade (teste de White), autocorrelação (teste de Breusch-Godfrey) e, por fim, estabilidade das raízes do polinômio AR. Todos os testes foram realizados e confirmaram a robustez dos modelos rodados.

Em seguida, chegando ao modelo adequado, analisou-se o impacto, nessas variáveis macroeconômicas, de um choque em cada variável contábil. Essa análise é possível por meio da IRF, que sintetiza o comportamento das séries incluídas no modelo VAR, em resposta a um choque exógeno em uma das variáveis sobre as demais do sistema (Sanches, Zanin, Alves \& Jacomini, 2016). Nesse sentido, as funções de impulso-resposta mostram como um impulso ou uma inovação numa dada variável tem efeitos sobre as demais (Triches \& Fiorentin, 2018). Ainda conforme Triches e Fiorentin (2018), a IRF pode ser expressa pela seguinte Equação (2):

$$
Y_{t}=\mu+\varepsilon_{t}+\Psi_{1} \varepsilon_{t-1}+\Psi_{2} \varepsilon_{t-2}+\cdots
$$

Com isso, a matriz $\Psi_{s}$ é interpretada pela Equação (3):

$$
\Psi_{s}=\frac{d y_{t+s}}{d e_{t}^{\prime}}
$$


Nessa última equação, $\Psi_{S}$ refere-se a uma matriz de multiplicadores dos efeitos de uma inovação ou choque sobre as variáveis endógenas. As linhas e colunas da referida matriz captam os resultados de uma inovação $\varepsilon_{\mathrm{t}}$ no valor da i-ésima variável no tempo $t+s$ (Triches \& Fiorentin, 2018).

Além da análise da IRF, realizou-se a decomposição da variância, que indica qual porcentagem da variância do erro de previsão decorre de cada variável endógena ao longo do horizonte da previsão (Sibin, Silva Filho \& Ballini, 2016). A decomposição da variância explica o quanto uma variável afeta a variância de outra variável (Pereira, Melo \& Xavier, 2017). A decomposição de variância de erro de previsão, segundo Farias (2008), responde à seguinte pergunta: Qual proporção da variância do erro de previsão ao prever $X_{T+h}$ é devida ao choque estrutural $\eta_{j}$ ?. A Equação (4) é a demonstração algébrica dessa questão (Farias, 2008):

$$
X_{T+h}-X_{T+h \mid T}=\sum_{s=0}^{h-1} \Theta_{s} \eta_{t+h-s}
$$

Para uma variável específica $X_{i, T+h}$, o erro de previsão tem a forma dada pela Equação (5):

$$
X_{i, T+h}-X_{i, T+h \mid T}=\sum_{s=0}^{h-1} \Theta_{i 1}^{S} \eta_{1, t+h-s}+\cdots+\sum_{s=0}^{h-1} \Theta_{i n}^{S} \eta_{n, t+h-s}
$$

Considerando que os erros estruturais são ortogonais, a variância do erro de previsão hpassos à frente é dada pela Equação (6):

$$
\operatorname{var}\left(X_{i, T+h}-X_{i, T+h \mid T}\right)=\sigma_{\eta \mathrm{j}}^{2} \sum_{s=0}^{h-1}\left(\Theta_{i 1}^{S}\right)^{2}+\sigma_{\eta \mathrm{j}}^{2} \sum_{s=0}^{h-1}\left(\Theta_{i n}^{S}\right)^{2}
$$

Em que $\sigma_{\eta j}^{2}=\operatorname{var}\left(\eta_{j t}\right)$. Por meio da Equação (7), observa-se que parte da $\operatorname{var}\left(X_{i, T+h}-\right.$ $\left.X_{i, T+h \mid T}\right)$, devido ao choque $\eta_{j}$, é então:

$$
D V E P_{i, j}(h)=\frac{\sigma_{\eta j}^{2} \sum_{s=0}^{h-1}\left(\Theta_{i j}^{S}\right)^{2}}{\sigma^{2} \sum_{s=0}^{h-1}\left(\Theta_{i 1}^{S}\right)^{2}+\cdots \sigma^{2} \sum_{s=0}^{h-1}\left(\Theta_{i n}^{S}\right)^{2}} i, j=1,2, \ldots, n .(7)
$$

Por fim, após a análise da decomposição da variância, realizou-se o teste de causalidade de Granger, para identificar a direção da causalidade entre as variáveis analisadas nos modelos. Segundo Cavalcanti (2010), uma variável $X$ causa outra variável $Z$, no sentido de Granger, se a observação de $X$ no presente ou no passado ajuda a prever os valores futuros de $Z$ para algum horizonte de tempo. O teste de causalidade de Granger é operacionalizado por meio de um modelo de VAR, que verifica as interações da relação dinâmica entre as variáveis com as especificações apresentadas nas Equações (8) e (9) (Nunes, Costa Junior \& Meurer, 2005).

$$
\begin{aligned}
& \mathrm{X}_{t}=\sum_{i=1}^{n} \alpha_{i} Y_{t-i}+\sum_{j=1}^{n} \beta_{j} X_{t-j}+u_{1 t} \\
& \mathrm{Y}_{t}=\sum_{i=1}^{n} \lambda_{i} Y_{t-i}+\sum_{j=1}^{n} \delta_{j} X_{t-j}+u_{2 t}
\end{aligned}
$$


No caso dessas regressões, $\mathrm{X}$ e Y representam as séries sob análise. Com esse modelo é possível conhecer a relação dinâmica entre o tempo de reação das respostas de algumas variáveis ante os choques nas outras variáveis, além da direção e duração dessas respostas (Santana, Silva \& Ferreira, 2018).

\section{ANÁLISE E DISCUSSÃO DOS RESULTADOS}

\subsection{Análise das séries temporais}

As estatísticas descritivas relativas aos dados sob análise são apresentadas na Tabela 1.

Tabela 1

Estatísticas descritivas

\begin{tabular}{lccccccc}
\hline Variável & N & Média & Mediana & Mínimo & Máximo & Desvio-padrão & Coeficiente de variação \\
\hline PIB & 79 & 2,42 & 2,50 & $-5,50$ & 9,20 & 3,12 & 1,29 \\
Desemp. & 79 & 9,18 & 8,90 & 5,20 & 13,70 & 2,34 & 0,25 \\
Selic & 79 & 13,10 & 12,55 & 5,66 & 24,75 & 4,71 & 0,36 \\
CXOP & 79 & 3,41 & 4,46 & 0,00 & 4,85 & 1,98 & 0,58 \\
Ebit & 79 & 4,61 & 4,63 & 3,95 & 4,93 & 0,21 & 0,05 \\
LL & 79 & 4,33 & 4,38 & 3,49 & 4,67 & 0,26 & 0,06 \\
PL & 79 & 5,61 & 5,65 & 5,36 & 5,81 & 0,16 & 0,03 \\
\hline
\end{tabular}

Nota. PIB: Produto Interno Bruto; Desemp.: Taxa de Desemprego; Selic: Sistema Especial de Liquidação e de Custódia - Taxa Básica de Juros da Economia; CXOP: Caixa Operacional; Ebit: earnings before interest and taxes lucro antes dos juros e tributos; LL: lucro líquido; PL: patrimônio líquido.

Fonte: Dados da pesquisa (2020).

As variáveis possuem grande amplitude. Essa condição é interessante para a pesquisa, visto que uma baixa variabilidade teria pouco a acrescentar às discussões ligadas ao tema. Explorar a análise com dados mais variados pode contribuir para fomentar discussões relevantes acerca do fenômeno estudado. Por exemplo, o PIB, no período analisado, varia entre -5,5 e 9,2. Os níveis de desemprego também possuem grande amplitude, de 5,2 a 13,7. E o mesmo ocorre com todas as demais variáveis. Essa variabilidade, como dito, pode reportar importantes achados para a pesquisa.

Consoante ao exposto na metodologia (seção 3), antes de iniciar a análise, deve-se testar a estacionariedade, o que, neste estudo, foi feito por meio do teste de Dickey-Fuller aumentado. Ao se trabalhar com séries temporais, há necessidade de se certificar que as séries são estacionárias, evitando, assim, regressões espúrias e inferências equivocadas. Nesse sentido, quando uma série temporal possui raiz unitária, as previsões se tornam imprecisas e tendenciosas (Silveira, Mattos \& Konrath, 2017).

As séries sob análise apresentaram raiz unitária, ou seja, mostraram-se não estacionárias. Com isso, aplicou-se a primeira diferença em cada uma das séries, de modo que, com isso, todas mostraram-se estacionárias (Tabela 2).

Tabela 2

Teste de estacionariedade - Dickey-Fuller

\begin{tabular}{lccccc}
\hline Série & $\mathrm{Z}(\mathrm{t})$ & $1 \%$ & $5 \%$ & $10 \%$ & Prob. \\
\hline CXOP & $-15,996$ & $-3,544$ & $-2,909$ & $-2,590$ & 0,0000 \\
Ebit & $-15,127$ & $-3,544$ & $-2,909$ & $-2,590$ & 0,0000 \\
LL & $-15,735$ & $-3,544$ & $-2,909$ & $-2,590$ & 0,0000 \\
PL & $-15,758$ & $-3,544$ & $-2,909$ & $-2,590$ & 0,0000 \\
PIB & $-11,329$ & $-3,544$ & $-2,909$ & $-2,590$ & 0,0000 \\
Desemp. & $-13,051$ & $-3,544$ & $-2,909$ & $-2,590$ & 0,0000 \\
\hline
\end{tabular}




\begin{tabular}{|c|c|c|c|c|c|}
\hline Selic & $-10,989$ & $-3,544$ & $-2,909$ & $-2,590$ & 0,0000 \\
\hline
\end{tabular}

Nota. PIB: Produto Interno Bruto; Desemp.: Taxa de Desemprego; Selic: Sistema Especial de Liquidação e de Custódia - Taxa Básica de Juros da Economia; CXOP: Caixa Operacional; Ebit: earnings before interest and taxes lucro antes dos juros e tributos; LL: lucro líquido; PL: patrimônio líquido.

Fonte: Dados da pesquisa (2020).

\subsection{Validade e análise dos modelos VAR}

Uma vez que as séries temporais mostraram-se estacionárias, deve-se identificar a quantidade de lags do modelo VAR. Para tanto, empregam-se critérios como AIC, HQIC e SBIC, de acordo com o discutido na metodologia (seção 3). No caso dos testes encaminhados nesta pesquisa, para ambos os modelos (PIB, SELIC e Desemprego), a quantidade de lags reportada foi de quatro defasagens. O resultado dos testes e os critérios empregados são demonstrados na Tabela 3 .

Tabela 3

\section{Lags do modelo VAR}

\begin{tabular}{|c|c|c|c|c|c|c|c|c|}
\hline \multicolumn{9}{|c|}{ PIB } \\
\hline $\operatorname{lag}$ & $\mathbf{L L}$ & LR & df & $\mathbf{p}$ & FPE & AIC & HQIC & SBIC \\
\hline 4 & -3856.11 & $209.47 *$ & 36 & 0 & $5.0 \mathrm{e}+41 *$ & $112.848 *$ & $114.749 *$ & $117.629 *$ \\
\hline \multicolumn{9}{|c|}{ SELIC } \\
\hline 4 & -3818.15 & $218.05 *$ & 36 & 0.000 & $1.7 \mathrm{e}+41 *$ & $111.779 *$ & $113.68 *$ & $116.559 *$ \\
\hline \multicolumn{9}{|c|}{ DESEMPREGO } \\
\hline 4 & -3784.74 & $202.72 *$ & 36 & 0 & $6.7 e+40 *$ & $110.838 *$ & $112.739 *$ & $115.618 *$ \\
\hline
\end{tabular}

Fonte: Dados da pesquisa (2020).

Verifica-se que nos “*” indicados em cada um dos modelos, segundo todos os critérios de cálculo a quantidade de lags indicada nos testes é de 4 defasagens. Como os dados são trimestrais, isso refere-se a 1 ano. Com isso, ao rodar os modelos de vetores autorregressivos (VAR), essa quantidade de lags foi adotada. Considerando que a análise gira em torno da IRF e da decomposição da variância, a saída do modelo VAR será omitida, primeiro por ser de pouca relevância para a discussão realizada e, segundo, por questões de espaço, dado que são tabelas grandes, que ocupariam demasiado espaço e nada acrescentariam à discussão. Todos os modelos atenderam os testes dos resíduos, conforme apresentado na metodologia (seção 3).

Na Tabela 4 é evidenciada a decomposição da variância para as variáveis Selic, PIB e desemprego. Essa tabela complementa as Figuras 1, 2 e 3.

A Figura 1 apresenta a IRF para a Selic. Conforme se observa, um aumento no caixa operacional das empresas tem um efeito inicial positivo, fazendo a Selic subir nos primeiros trimestres, porém, próximo ao quinto trimestre o efeito se inverte, fazendo com que a taxa diminua. Posteriormente, o choque se dissipa e aproximadamente no décimo trimestre há um novo efeito na Selic, fazendo-a subir e, logo em seguida, cair.

Quanto ao Ebit, o aumento é sentido logo nos trimestres iniciais, elevando ligeiramente a taxa Selic, seguindo-se uma queda que a faz retornar para próximo dos patamares iniciais. Após isso, o efeito é dissipado. Já um aumento no LL tem efeito próximo ao quinto trimestre, achados semelhantes aos encontrados por Shivakumar (2007), Kothari et al. (2013) e Shivakumar e Urcan (2017), cujos resultados apontaram que os lucros das organizações afetam positivamente a inflação futura. 
Tabela 4

Decomposição da variância - SELIC, PIB e Desemprego

\begin{tabular}{|c|c|c|c|c|c|c|c|c|c|c|c|c|c|c|c|}
\hline \multicolumn{6}{|c|}{ SELIC } & \multicolumn{5}{|c|}{ PIB } & \multicolumn{5}{|c|}{ Desemprego } \\
\hline $\mathbf{T}$ & CXOP & Ebit & $\mathbf{L L}$ & PL & $\Sigma^{\mathbf{a}}$ & CXOP & Ebit & $\mathbf{L L}$ & PL & $\Sigma$ & CXOP & Ebit & $\mathbf{L} \mathbf{L}$ & PL & $\Sigma$ \\
\hline 0 & 0 & 0 & 0 & 0 & $0,00 \%$ & 0 & 0 & 0 & 0 & $0,00 \%$ & 0 & 0 & 0 & 0 & $0,00 \%$ \\
\hline 1 & 0 & 0 & 0 & 0 & $0,00 \%$ & 0 & 0 & 0 & 0 & $0,00 \%$ & 0 & 0 & 0 & 0 & $0,00 \%$ \\
\hline 2 & 0 & 0 & 0 & 0 & $0,35 \%$ & 0,01 & 0 & 0,03 & 0 & $4,51 \%$ & 0 & 0 & 0,03 & 0,02 & $4,53 \%$ \\
\hline 3 & 0 & 0,01 & 0 & 0,01 & $2,49 \%$ & 0,03 & 0,02 & 0,08 & 0 & $13,53 \%$ & 0,01 & 0 & 0,08 & 0,03 & $11,92 \%$ \\
\hline 4 & 0 & 0,02 & 0 & 0,02 & $3,96 \%$ & 0,03 & 0,04 & 0,08 & 0,02 & $16,66 \%$ & 0,03 & 0 & 0,09 & 0,03 & $15,24 \%$ \\
\hline 5 & 0,01 & 0,02 & 0,03 & 0,01 & $7,44 \%$ & 0,03 & 0,04 & 0,07 & 0,04 & $17,97 \%$ & 0,06 & 0 & 0,08 & 0,03 & $17,41 \%$ \\
\hline 6 & 0,03 & 0,02 & 0,07 & 0,01 & $13,16 \%$ & 0,02 & 0,03 & 0,08 & 0,06 & $19,80 \%$ & 0,07 & 0 & 0,08 & 0,04 & $19,39 \%$ \\
\hline 7 & 0,03 & 0,01 & 0,09 & 0,01 & $14,86 \%$ & 0,03 & 0,03 & 0,08 & 0,08 & & 0,07 & 0 & 0,08 & 0,05 & $20,35 \%$ \\
\hline 8 & 0,03 & 0,01 & 0,09 & 0,02 & & 0,03 & 0,04 & 0,09 & 0,07 & & 0,07 & 0 & 0,09 & 0,05 & $21,32 \%$ \\
\hline 9 & 0,03 & 0,01 & 0,09 & 0,02 & $16,43 \%$ & 0,02 & 0,04 & 0,08 & 0,08 & $21,98 \%$ & 0,09 & 0 & 0,09 & 0,05 & $22,73 \%$ \\
\hline 10 & 0,03 & 0,01 & 0,09 & 0,02 & $16,60 \%$ & 0,02 & 0,03 & 0,08 & 0,09 & $23,39 \%$ & 0,09 & 0 & 0,09 & 0,06 & $24,23 \%$ \\
\hline 11 & 0,05 & 0,01 & 0,1 & 0,02 & $18,05 \%$ & 0,02 & 0,03 & 0,08 & 0,11 & $25,09 \%$ & 0,09 & 0 & 0,09 & 0,1 & $27,07 \%$ \\
\hline 12 & 0,06 & 0,01 & 0,1 & 0,03 & $20,28 \%$ & 0,02 & 0,03 & 0,08 & 0,11 & $25,26 \%$ & 0,09 & 0 & 0,08 & 0,12 & $29,12 \%$ \\
\hline 13 & 0,07 & 0,01 & 0,1 & 0,02 & $20,88 \%$ & 0,02 & 0,03 & 0,08 & 0,11 & $24,89 \%$ & 0,1 & 0 & 0,08 & 0,12 & $30,71 \%$ \\
\hline 14 & 0,07 & 0,02 & 0,1 & 0,03 & $21,07 \%$ & 0,02 & 0,03 & 0,08 & 0,11 & $25,01 \%$ & 0,1 & 0,01 & 0,08 & 0,13 & $31,67 \%$ \\
\hline 15 & 0,07 & 0,02 & 0,11 & 0,03 & $21,40 \%$ & 0,02 & 0,03 & 0,08 & 0,11 & $25,28 \%$ & 0,1 & 0,01 & 0,08 & 0,13 & $32,30 \%$ \\
\hline 16 & 0,07 & 0,02 & 0,11 & 0,03 & $21,60 \%$ & 0,02 & 0,03 & 0,08 & 0,11 & $25,22 \%$ & 0,1 & 0,01 & 0,08 & 0,13 & $32,63 \%$ \\
\hline 17 & 0,07 & 0,02 & 0,11 & 0,03 & $22,28 \%$ & 0,02 & 0,03 & 0,08 & 0,11 & $25,13 \%$ & 0,11 & 0,01 & 0,08 & 0,14 & $33,46 \%$ \\
\hline 18 & 0,07 & 0,02 & 0,11 & 0,04 & $23,15 \%$ & 0,02 & 0,03 & 0,08 & 0,12 & $25,31 \%$ & 0,11 & 0,01 & 0,08 & 0,14 & $34,40 \%$ \\
\hline 19 & 0,07 & 0,02 & 0,1 & 0,04 & $23,29 \%$ & 0,02 & 0,03 & 0,08 & 0,12 & $25,51 \%$ & 0,11 & 0,02 & 0,08 & 0,15 & $35,05 \%$ \\
\hline 20 & 0,07 & 0,02 & 0,11 & 0,04 & $23,48 \%$ & 0,02 & 0,03 & 0,08 & 0,12 & $25,50 \%$ & 0,11 & 0,02 & 0,08 & 0,15 & $35,18 \%$ \\
\hline
\end{tabular}

Nota. CXOP: caixa operacional; Ebit; earnings before interest and taxes - lucro antes dos juros e tributos; LL: lucro líquido; PL: patrimônio líquido; $\Sigma^{\mathrm{a}}$ : somatório das variâncias das variáveis contábeis.

Fonte: Dados da pesquisa (2020).

Após este aumento, a taxa reduz e logo em seguida aumenta, seguindo-se nova queda próximo ao décimo trimestre. Para as demais janelas de tempo, seguem-se algumas oscilações, com a dissipação do efeito.

Kothari et al. (2013) verificaram que as informações agregadas resultantes dos lucros antecipam as notícias de inflação nos períodos subsequentes. Os autores justificam, dentre outros motivos, que os empréstimos e os lucros estão correlacionados positivamente, isto é, os fornecedores de capital (bancos) visualizam menor risco nos empréstimos à medida que a lucratividade das entidades aumenta, contribuindo para um aumento dos empréstimos. Em outras palavras, uma maior disponibilidade de crédito no mercado leva a uma maior demanda por serviços e produtos, acarretando aumento da inflação.

Por fim, um aumento no PL das empresas tem efeito positivo inicial, seguido de um retorno ao estado inicial, impactando os trimestres seguintes (próximo ao décimo), seguindo ainda efeitos menores nos trimestres seguintes até se dissipar. 


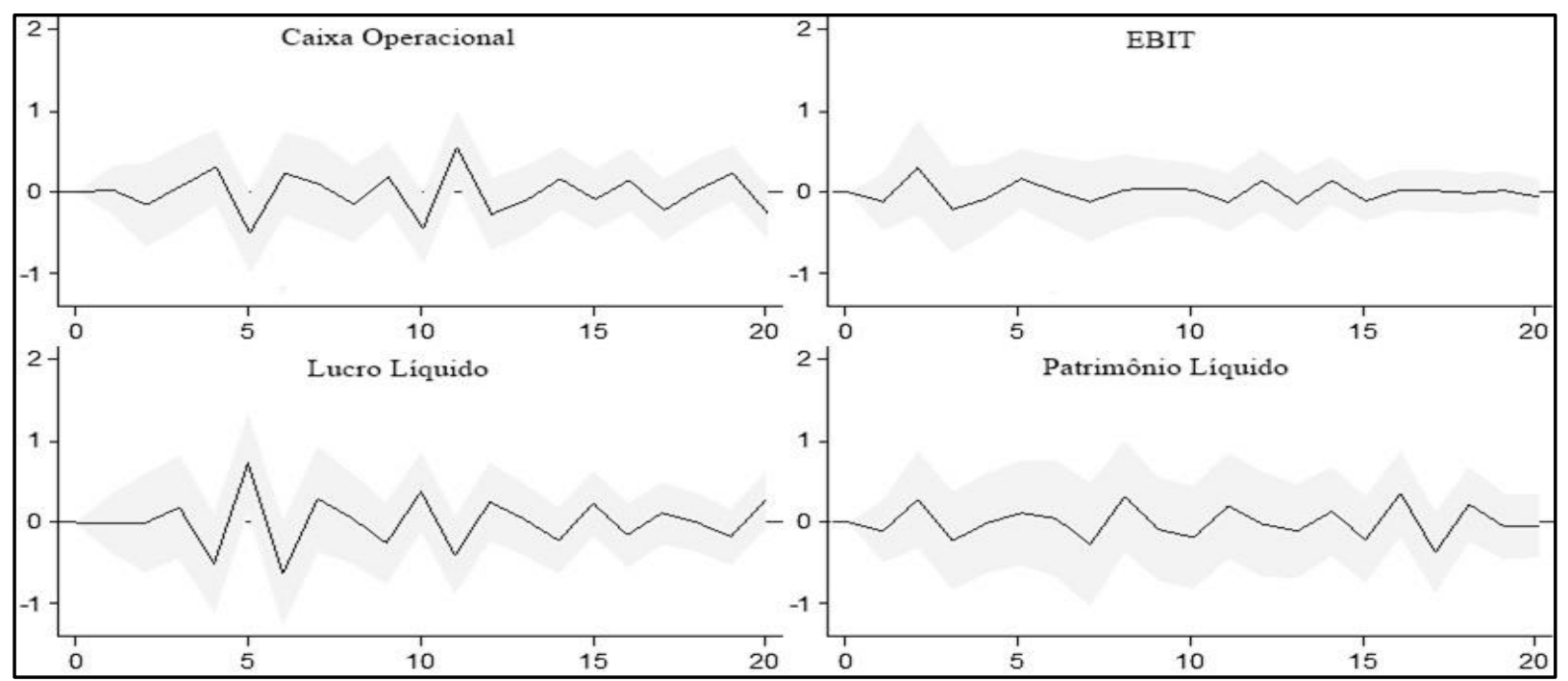

Figura 1. Função impulso-resposta (IRF) para a Selic

Fonte: Dados da pesquisa (2020).

Nota-se que a informação contábil apresenta os maiores choques na variável macroeconômica (Selic) nos cinco primeiros trimestres, os quais, em seguida, se dissipam. A análise da IRF das variáveis contábeis em relação à Selic evidencia que na maior parte do tempo, o efeito do aumento dos números contábeis gera diminuições na Selic, ou seja, reduções na taxa de juros básica da economia. Com isso, ressalta-se a existência de carga informacional acerca da economia real contida na informação da contabilidade, corroborando os achados de Shivakumar (2007), Cready e Gurun (2010), Kothari et al. (2013) e Shivakumar e Urcan (2017).

A Tabela 4 complementa a análise dos gráficos da IRF para todas as variáveis. No tocante à Selic, a informação contábil explica, quatro trimestres à frente, 3,96\% de variância, e esses números aumentam com o passar do tempo. Esse fato evidencia que a informação contábil das empresas carrega um importante componente da economia real, capaz de contribuir para a melhor explicação dos fenômenos macroeconômicos vivenciados (Shivakumar, 2007; Cready \& Gurun, 2010; Kothari et al., 2013). Destaca-se o peso do LL na decomposição da variância da Selic, apresentando, desde os trimestres iniciais, um peso relevante para sua explicação.

A respeito do modelo que verifica o efeito que o PIB reflete a partir das variáveis contábeis, observa-se que o seu comportamento apresenta a seguinte característica, conforme evidencia a Figura 2: quando há choque na variável caixa operacional, imediatamente surge um pequeno efeito positivo no PIB, seguido de um efeito negativo e outro ligeiramente positivo, dissipando-se após isso. Tudo isso ocorre antes do quinto trimestre.

Era de se esperar que, com uma maior disponibilidade no caixa nas empresas, o efeito no PIB fosse estritamente positivo, porém os dados mostram que, no Brasil e no período analisado, essa relação linear não se observa. Isso pode indicar que o caixa excedente dessas empresas talvez não fosse empregado em atividades produtivas, que contribuíssem para o crescimento do PIB.

Acerca do Ebit, o comportamento é muito similar ao do caixa operacional, porém, quando há crescimento do Ebit das empresas, o efeito positivo no PIB é maior do que o negativo, ocorrendo antes do quinto trimestre. Depois disso, o Ebit ainda causa algum impacto no PIB, porém logo ele é dissipado. A IRF mostra que na maior parte do tempo o efeito do Ebit sobre o PIB é positivo, indicando que a variável carrega informações relativas ao crescimento da economia.

Quanto ao LL, tal qual ocorre com o Ebit, na maior parte do tempo aumentos de lucro das empresas geram crescimento econômico, dado que a IRF evidencia efeitos positivos do lucro corporativo até próximo ao décimo trimestre, dissipando-se em seguida. Ou seja, o lucro carrega forte evidência de crescimento econômico por vários trimestres à frente. Com isso, há forte evidência de que essa informação é bastante útil para estimar futuros crescimentos econômicos. 
Estes achados são consistentes com os encontrados nos trabalhos de Konchitchki e Patatoukas (2014a), Konchitchki e Patatoukas (2014b), Brito (2017), Silva et al. (2018) e Silva (2019), os quais apresentaram que o lucro causa uma influência positiva no lucro, demonstrando assim a capacidade preditiva da lucratividade das organizações no nível macroeconômico, notadamente no PIB.

Por fim, no tocante ao PL das empresas e ao PIB, o sinal se apresentou oscilante em todo período da amostra. Há grande variabilidade nos movimentos do PIB quando da movimentação do PL. O efeito é dissipado aproximadamente no décimo trimestre. Brito (2017) também encontrou maior influência nos primeiros dez trimestres, isto é, a influência da variável contábil sobre a macroeconômica deu-se dentro de um horizonte de um ano.

A Tabela 4 também apresenta a decomposição da variância para o PIB. Verifica-se que no quarto trimestre o conjunto de variáveis contábeis modelado explica 16,66\% das variações do PIB. Em oito trimestres, esse número passa para $22,41 \%$ e segue avançando com o passar do tempo até chegar a 25,5\%. Observa-se que a variabilidade do PIB é explicada em maior intensidade pelo LL e pelo PL. Brito (2017) também encontrou que tanto o LL quanto o PL, em seus respectivos modelos, conseguiram explicar em maior magnitude a variância do PIB que as demais variáveis do modelo.
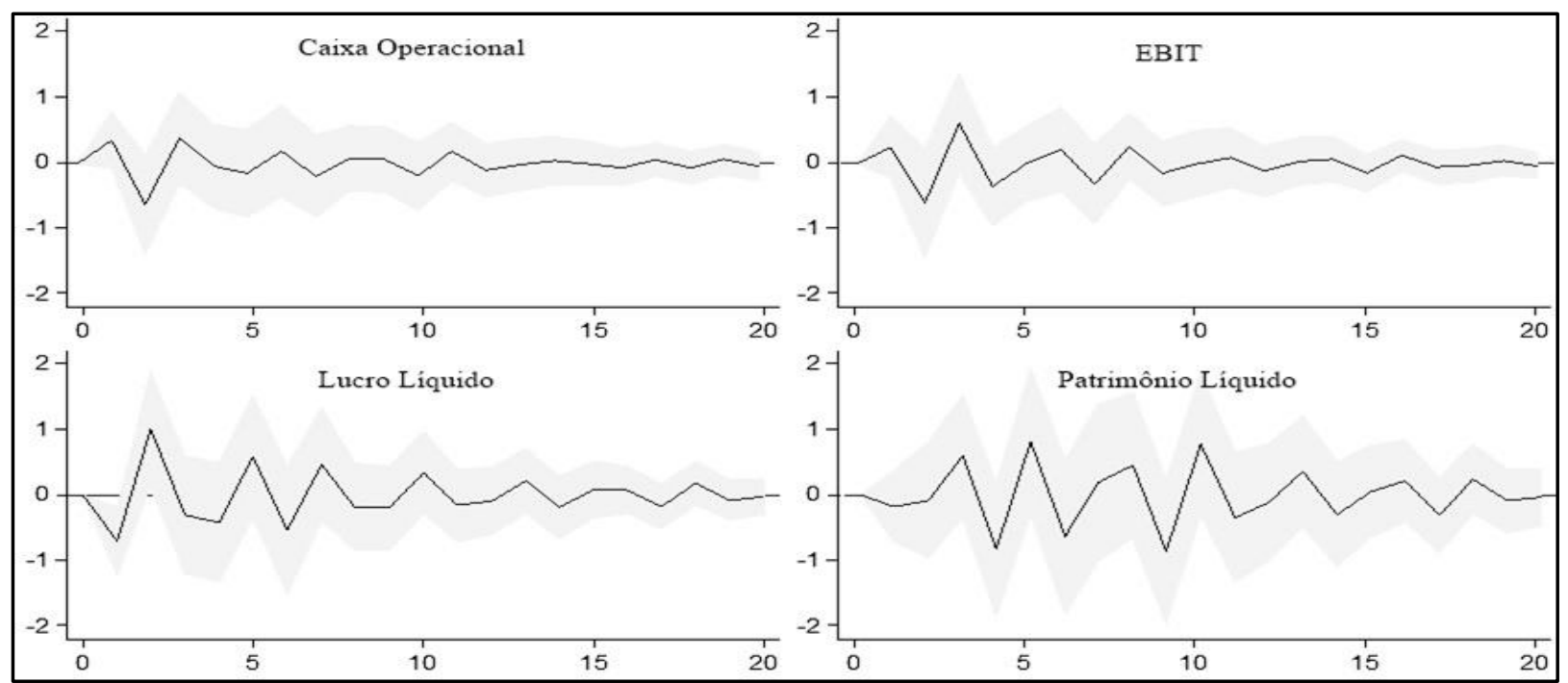

Figura 2. Função impulso-resposta (IRF) para o PIB

Fonte: Dados da pesquisa (2020).

As variáveis contábeis do modelo contribuem para a explicação do PIB (Konchitchki \& Patatoukas, 2014a; Konchitchki \& Patatoukas, 2014b; Kuosmanen \& Vataja, 2014; Brito, 2017; Silva et al, 2018; Silva, 2019). Nos trimestres iniciais a contribuição é menor, mas, à medida que passam os trimestres, o poder explicativo aumenta, evidenciando que a informação contábil tem poder explicativo e carrega informações sobre a economia real.

Por fim, a Figura 3 evidencia a IRF das variáveis contábeis em relação à variável macroeconômica desemprego. Analisando-se o caixa operacional em relação ao desemprego, verifica-se uma sucessão de efeitos intensos no desemprego pelo menos até o décimo trimestre, com redução posterior e consequente dissipação. Verificando a IFR, parece nítido que um aumento de caixa causa, na maior parte do tempo, efeitos negativos no desemprego, de modo que é possível concluir-se que quanto mais caixa à disposição das empresas, menores os níveis de desemprego na economia. 


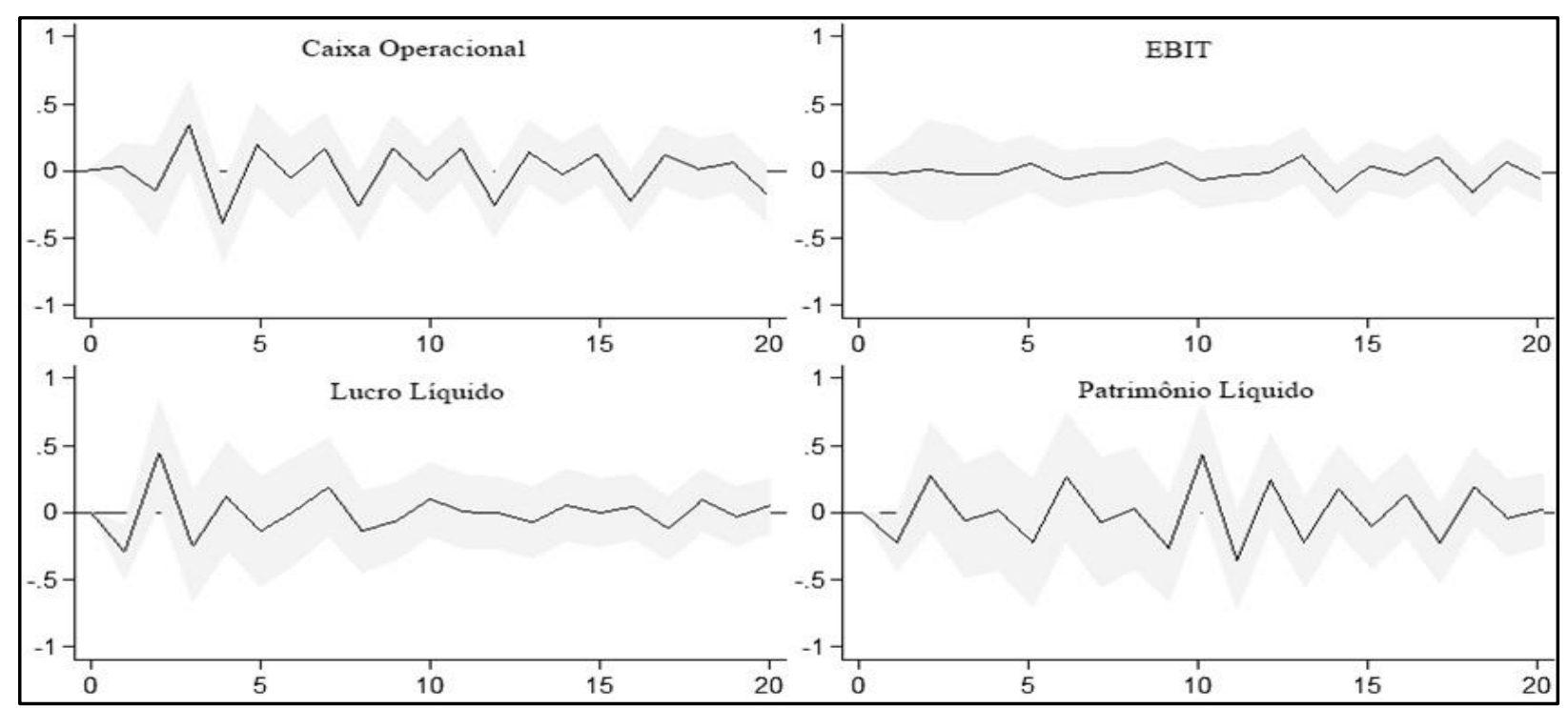

Figura 3. Função impulso-resposta IRF para Desemprego

Fonte: Dados da pesquisa (2020).

Esse achado é bastante coerente, pois, à medida que as empresas dispõem de maiores níveis de caixa, é natural que existam mais recursos a serem empregados em atividades produtivas. Maior produção requer mais mão de obra, o que impacta diretamente nos níveis de desemprego. Embora a IRF evidencie alguns picos positivos no desemprego (ou seja, aumentos), nitidamente o efeito, ao longo da maior parte do tempo, é negativo, sendo possível, portanto, inferir que a informação contábil relativa ao caixa operacional das empresas carrega carga informacional real a respeito dos níveis de desemprego na economia.

Quanto ao Ebit, verifica-se que um choque dessa variável tem um efeito mais modesto no desemprego. Esse achado não causa estranheza, até porque uma empresa não necessariamente precisa produzir mais para que sejam verificados maiores níveis de Ebit. Esse intento pode ser obtido com redução de custos, cortes de pessoal, otimizações, dentre outras ações. Conforme se verifica, um choque no Ebit tem pouco efeito nos níveis de desemprego.

No que se refere ao PL e ao LL, percebem-se impactos tanto positivos quanto negativos ao longo do período amostral. Um choque negativo provocado nos primeiros trimestres demonstra que um aumento na lucratividade incorre em uma diminuição na taxa de desemprego. De acordo com Hann et al. (2017), a procura de mão de obra das organizações pode ser determinada pela demanda de produtos e pela forma de sua função de produção e, em caso de lucratividade positiva, é provável que leve à investimentos e contração, ou seja, provocando queda na taxa de desemprego.

Analisando a decomposição da variância do desemprego, nota-se que as variáveis contábeis, quatro trimestres à frente, explicam $15,24 \%$ da sua variabilidade, muito disso puxado pelo LL. Após isso, o PL curiosamente apresenta o maior poder explicativo das variações do desemprego.

Fica aqui evidenciado que as variáveis contábeis, tal qual ocorreu com os modelos anteriores, oferecem um bom conjunto explicativo para as variações na variável macroeconômica (desemprego), corroborando os achados de Hann et al. (2017) e Nallareddy e Ogneva (2017). Com isso, a informação disponibilizada pela contabilidade pode ser empregada para antecipar eventuais movimentos dos níveis de desemprego na economia, visto que as empresas servem como uma espécie de termômetro, emitindo sinais úteis para a estimação dos níveis de desemprego (e outras variáveis econômicas) dado que a informação contábil carrega, em si, informações sobre a economia real do país. 


\subsection{Causalidade de Granger}

Além da análise do impulso-resposta e da decomposição da variância, rodou-se um teste de causalidade de Granger, visando identificar relações de causalidade e a direção entre as variáveis estudadas. O resultado do teste de Granger é apresentado na Tabela 5.

Tabela 5

\section{Causalidade de Granger}

\begin{tabular}{ccc|ccc|ccc}
\hline $\mathbf{V M}^{\mathbf{a}}$ & $\mathbf{V C}^{\mathbf{b}}$ & Prob>chi2 & $\mathbf{V M}^{\mathbf{a}}$ & $\mathbf{V C}^{\mathbf{b}}$ & Prob>chi2 & VM$^{\mathbf{a}}$ & $\mathbf{V C}^{\mathbf{b}}$ & Prob>chi2 \\
\hline Desemp. & CXOP & 0,002 & Selic & CXOP & 0,002 & PIB & CXOP & 0,002 \\
Desemp. & Ebit & 0,002 & Selic & Ebit & 0,002 & PIB & Ebit & 0,002 \\
Desemp. & LL & 0,013 & Selic & LL & 0,013 & PIB & LL & 0,013 \\
Desemp. & PL & 0,070 & Selic & PL & 0,070 & PIB & PL & 0,070 \\
Desemp. & Todas & 0,000 & Selic & Todas & 0,000 & PIB & Todas & 0,000 \\
\hline
\end{tabular}

Nota. $\mathrm{VM}^{\mathrm{a}}$ : variável macroeconômica; $\mathrm{VC}^{\mathrm{b}}$ : variável contábil; CXOP: caixa operacional; Ebit: earnings before interest and taxes - lucro antes dos juros e tributos; LL: lucro líquido; PL: patrimônio líquido.

Fonte: Dados da pesquisa (2020).

Evidentemente, o que interessa, para fins da pesquisa, é apenas a causalidade entre as variáveis contábeis e as econômicas. Portanto, a tabela foi em grande parte omitida, não sendo apresentada a causalidade entre variáveis contábeis. Conforme se verifica na Tabela 5, em todos os casos, as variáveis contábeis causam as variáveis macroeconômicas. Esse achado complementa a análise da IRF e da decomposição da variância anteriormente tratada.

Note-se que em todos os casos, a causalidade é estatisticamente significativa. Na maioria dos casos, a significância é de $1 \%$, em alguns de $5 \%$ e outros (poucas ocorrências) de 10\%. De toda forma, as variáveis contábeis causam as econômicas, o que se infere com segurança estatística.

\section{CONSIDERAÇÕES FINAIS}

Esse estudo teve como objetivo analisar o efeito, nas variáveis macroeconômicas, de choques na informação contábil para o cenário brasileiro. Especificamente, buscou-se avaliar se choques em determinadas variáveis contábeis (LL, Ebit, PL e caixa operacional) impactavam, e em que medida, o PIB, a SELIC e o desemprego, que constituem o conjunto de variáveis macroeconômicas de interesse da pesquisa. Em síntese, investiga-se se a informação contábil carrega dados sobre a economia real e se é útil para prever movimentos de variáveis macroeconômicas.

Por qual razão interessa um estudo dessa natureza? Importa testar uma suposição, feita por Ball e Brown (1968), de que a informação contábil possui utilidade em diferentes contextos. Nesse sentido, pesquisas analisando a relevância da informação contábil são recorrentes, em especial sob a ótica de decisões do mercado financeiro, sobre estrutura de capital, como insumo para previsão de lucros futuros das firmas, dentre outros empregos consagrados pela literatura. No entanto, uma linha de investigação pouco explorada emergiu recentemente, estudando o impacto da informação contábil em informações macroeconômicas.

Conforme foi discutido na seção de apresentação dos resultados, choques nas variáveis contábeis analisadas impactam, em maior ou menor grau, as variáveis macroeconômicas. Além da IRF, analisou-se a decomposição da variância de cada uma dessas variáveis macroeconômicas, e em todos os casos as variáveis contábeis contribuem para sua explicação, de novo, em maior ou menor grau. Isso reforça o que foi discutido na análise da IRF sobre a capacidade informativa dessas variáveis contábeis e o fato de que elas carregam informações úteis para explicação de fenômenos econômicos do mundo real. 
Também realizou-se uma análise da causalidade que apontou que as variáveis contábeis estudadas causam, no sentido de Granger, todas as variáveis econômicas analisadas. Isso reforça os achados discutidos e constitui mais um importante indício do tema central da discussão da pesquisa: de que a informação contábil carrega em si elementos da economia real, sendo capaz, portanto, de explicá-la em parte.

Estes resultados se alinham aos encontrados nos estudos de Konchitchki e Patatoukas (2014a), Konchitchki e Patatoukas (2014b), Brito (2017), Silva et al (2018) e Silva (2019), para o PIB; Shivakumar (2007), Cready e Gurun (2010), Kothari et al. (2013), Shivakumar e Urcan (2017), para a inflação; e, por fim, Hann et al. (2017), Nallareddy e Ogneva (2017), para a taxa de desemprego. Tais achados são relevantes, pois abrem perspectivas para melhor estimação dessas variáveis, bem como oportunidades para novas pesquisas. Com isso, analistas econômicos, e até mesmo governos, podem empregar essa informação para realizar melhores e mais refinadas estimativas dessa variável econômica.

Desta forma, o objetivo geral da pesquisa - analisar o efeito, nas variáveis macroeconômicas, de choques na informação contábil para o cenário brasileiro - foi plenamente atendido, uma vez que, conforme evidenciou a análise empírica, choques nas variáveis contábeis influenciam as variáveis macroeconômicas, algumas em maior grau (como o LL em relação à Selic), outras em menor grau (como o Ebit em relação ao desemprego). Os achados sugerem a efetiva influência da informação contábil sobre componentes macroeconômicos, contribuindo para uma melhor tomada de decisão, em especial de investimento e alocação de capitais, visto que é possível melhor compreender a dinâmica macroeconômica por meio das informações da contabilidade. Embora os resultados da pesquisa sejam robustos e importantes do ponto de vista prático e acadêmico, o estudo possui limitações. A primeira é que a análise foi apenas no contexto brasileiro. Uma análise com países da América Latina, ou mesmo com uma amostra de países de diferentes cenários econômicos, poderia reportar achados diferentes e novas constatações.

Além disso, no estudo optou-se por não deflacionar as variáveis. Trabalhar com variáveis deflacionadas pode gerar diferentes achados, o que serve, inclusive, como recomendação para futuras pesquisas. Por fim, o número de variáveis contábeis analisado é pequeno. Empreender uma pesquisa com um número maior de variáveis pode contribuir para identificar diferentes relações entre elas e a informação econômica. Buscar, justificadamente, um conjunto maior de variáveis contábeis pode lançar luz sobre novos achados, aprofundando discussões iniciadas nesta pesquisa.

Ainda, como sugestão para futuras investigações, pode-se buscar melhor compreender por qual razão o Ebit possui maior poder explicativo do que o LL para algumas variáveis e outras não, e assim por diante. Entender o motivo pelo qual em determinada situação certa variável explica mais as variações na informação econômica do que outra (que não constitui objeto desta pesquisa) contribuirá para o desenvolvimento da pesquisa no tema.

\section{REFERÊNCIAS}

Ball, R., \& Brown, P. (1968). An empirical evaluation of accounting income numbers. Journal of accounting research, 159-178.

Ball, R., \& Sadka, G. (2015). Aggregate earnings and why they matter. Journal of Accounting Literature, 34, 39-57.

Barboza, R. D. M., \& Zilberman, E. (2018). Os efeitos da incerteza sobre a atividade econômica no Brasil. Revista Brasileira de Economia, 72(2), 144-160.

Bloom, N., Floetotto, M., Jaimovich, N., Saporta-Eksten, I., \& Terry, S. J. (2012). Really uncertain business cycles (No. w18245). National Bureau of Economic Research. 
Brito, S. S. (2017). Informação contábil e crescimento econômico: estudo da relação entre o desempenho econômico-financeiro das empresas e o PIB. Dissertação de Mestrado em Ciências Contábeis, Universidade Estadual de Maringá, Maringá, PR, Brasil.

Cavalcanti, M. A. F. H. (2010). Identificação de modelos VAR e causalidade de Granger: uma nota de advertência. Economia Aplicada, 14(2), 251-260. https://dx.doi.org/10.1590/S141380502010000200008 .

Cready, W., \& U. Gurun. 2010. Aggregate Market Reaction to Earnings Announcements. Journal of Accounting Research, 48, 289-334.

Farias, H. P. (2008). Função resposta a impulso e decomposição da variância do erro de previsão aplicados às principais bolsas de valores. Dissertação de Mestrado, Universidade Federal de Lavras, Lavras, MG, Brasil.

Giordano, R., Momigliano, S., Neri, S., \& Perotti, R. (2007). The effects of fiscal policy in Italy: Evidence from a VAR model. European Journal of Political Economy, 23(3), 707-733.

Hann, R. N., Li, C., \& Ogneva, M. (2017). Another look at the macroeconomic information content of aggregate earnings: Evidence from the labor market. Available at SSRN 2993654.

Kalay, A., Nallareddy, S., \& Sadka, G. (2016). Uncertainty and sectoral shifts: The interaction between firm-level and aggregate-level shocks, and macroeconomic activity. Management Science, 64(1), 198-214.

Keynes, J. M. (1936). The General Theory of Employment, Interest and Money. Londres, Macmillan.

Konchitchki, Y., \& Patatoukas, P. N. (2014a). Accounting earnings and gross domestic product. Journal of Accounting and Economics, 57(1), 76-88.

Konchitchki, Y., \& Patatoukas, P. N. (2014b). Taking the pulse of the real economy using financial statement analysis: Implications for macro forecasting and stock valuation. The Accounting Review, 89(2), 669-694.

Kothari, S. P., \& Wasley, C. (2019). Commemorating the 50-Year Anniversary of Ball and Brown (1968): The Evolution of Capital Market Research over the Past 50 Years. Journal of Accounting Research, 57(5), 1117-1159.

Kothari, S. P., Shivakumar, L., \& Urcan, O. (2013). Aggregate earnings surprises and inflation forecasts. Unpublished Paper, MIT Sloan School of Management and London Business School.

Nallareddy, S., \& Ogneva, M. (2017). Predicting restatements in macroeconomic indicators using accounting information. The Accounting Review, 92(2), 151-182.

Nunes, M. S., Costa Junior, N. C., \& Meurer, R. (2005). A relação entre o mercado de ações e as variáveis macroeconômicas: uma análise econométrica para o Brasil. Revista Brasileira de Economia, 59(4), 585-607.

Pereira, G. C., Melo, A. S., \& Xavier, L. F. (2017). Efeitos da política de salário mínimo sobre o mercado de trabalho metropolitano: uma análise empírica a partir de vetores autorregressivos 
(var) - (2003-2015). Revista de Economia Contemporânea, 21(1), e172113. https://dx.doi.org/10.1590/198055272113

Sanches, A. L. R., Zanin, V., Alves, L. R. A., \& Jacomini, R. L. (2016). Formação de preços no mercado de milho da Região de Chapecó/SC-Brasil. Revista Espacios, 37(18).

Shivakumar, L. (2007). Aggregate Earnings, Stock Market Returns and Macroeconomic Activity: A Discussion of 'Does Earnings Guidance Affect Market Returns? The Nature and Information Content of Aggregate Earnings Guidance." Journal of Accounting and Economics, 44, 64-73.

Shivakumar, L., \& Urcan, O. (2017). Why does aggregate earnings growth reflect information about future inflation? The Accounting Review, 92(6), 247-276.

Sibin, B. H., Silva Filho, L. A., \& Ballini, R. (2016). Financiamento habitacional e seus impactos sobre os preços na construção civil brasileira. Revista Espacios, 37(20).

Silva, J. R. R. (2019). Informações contábeis e atividade econômica: a relação entre o desempenho das firmas e crescimento econômico do Brasil. Dissertação de Mestrado em Ciências Contábeis, Universidade Federal da Paraíba, PB, Brasil.

Silva, J. R. R., Paulo, E., Bianchi, M., \& Queiroz, D. B. (2018) Informações contábeis e atividade econômica: relação entre rentabilidade das firmas no crescimento econômico do Brasil. Anais do Congresso Anpcont, João Pessoa, PB, Brasil, 12.

Silveira, A. G., de Mattos, V. L. D., \& Konrath, A. C. (2017). Avaliação da estacionariedade e teste de cointegração em séries temporais o caso da demanda de energia elétrica residencial no brasil. RETEC-Revista de Tecnologias, 9(3).

Sistema IBGE de Recuperação Automática (SIDRA) (2020). Recuperado em 6 fevereiro, 2020, de http://sidra.ibge.gov.br

Triches, D., \& Fiorentin, G. P. (2018). Avaliação do regime de metas de inflação nos países da américa latina entre 2001 e 2014. Revista de Economia Contemporânea, 22(2). 